Article

\title{
The Linguistic Landscape of the Valencian Community: A Comparative Analysis of Bilingual and Multilingual Signs in Three Different Areas
}

\author{
Lucía Bellés-Calvera $\mathbb{D}$ \\ Department of History, Geography and Art, Universitat Jaume I, 12071 Castelló de la Plana, Spain; \\ lucia.belles@uji.es
}

Received: 10 May 2019; Accepted: 12 June 2019; Published: 16 June 2019

\begin{abstract}
During the last decades, the promotion of multilingualism has been key when designing linguistic policies in Europe. Previous research studies have focused on how languages are employed in fields such as education, media, and urban sites, among others. Bearing all this in mind, the aim of this paper is to analyse the linguistic landscapes of three municipalities located in a bilingual region in Spain, that of the Valencian Community. Thus, issues such as language contact, language dominance, and the languages used by a number of institutions on private and public signs were examined. As for the method, over 140 pictures of language signs were taken in order to examine language contact, language dominance, and the influence of official and foreign languages on private and public signs. The results suggest that the presence of languages may vary depending on the population living in these settings, the citizens' mother tongue, and the policy regarding the minority language. The findings also indicate that the power of the two co-official languages is reinforced by public signs, whereas rich linguistic diversity is shown in private signs. All in all, it can be stated that the linguistic policy in the Valencian Community is not homogeneous throughout the region.
\end{abstract}

Keywords: linguistic landscape; minority language; bilingualism; multilingualism; language contact

\section{Introduction}

In recent years, official institutions have regulated linguistic policies dealing with the protection of minority languages (European Parliament 2017) and the introduction of foreign languages within a given territory, particularly in Europe (European Commission 2015). In this sense, bilingual and multilingual phenomena may occur in the linguistic landscape of an area.

This concept has been regarded as the "language of public road signs, advertising billboards, street names, place names, commercial shop signs, and public signs on government buildings which is combined to form the linguistic landscape of a given territory, region, or urban agglomeration" (Landry and Bourhis 1997, p. 25). These signs may be categorised into top-down or bottom-up depending on their nature. Top-down signs are those which have official status since they are issued by the government, whereas bottom-up signs are nonofficial signs regulated by private organisations or individuals.

Previous research studies have acknowledged bilingual and multilingual practices in urban sites (Cenoz and Gorter 2006; Gorter 2006; Huebner 2006; Ben-Rafael et al. 2006; Shohamy et al. 2010). Gorter (2006) compared the linguistic landscape of two commercial streets set in Basque Country and The Netherlands, giving special emphasis to the use of the minority language. The case study about multilingualism in some Israeli cities was based on the use of Hebrew, Arabic, and English on public and private signs, also known as top-down and bottom-up signs, respectively (Ben-Rafael et al. 2006). Another major contribution by Huebner (2006) explored language mixing in Bangkok. 
This paper focuses on language contact, language dominance, and the languages used on the private and public signs of three municipalities located in the Valencian Community: Benasal, Almazora, and Valencia.

Benasal, a small village set in the Castellón province, is a traditional Valencian-speaking area where most individuals have Valencian as their mother tongue. Its economy is mainly based on rural tourism and pig farming as well as on cheese and meat production.

Almazora is a town located in the southeast of the Castellón province. Even though Valencian has been the predominant language of the area, the linguistic repertoire of the city has increased due to several factors. These include waves of immigration in past decades as well as the promotion of Almazora as a tourist destination.

Valencia, which is the capital city of the Valencian Community and the third largest city in Spain, has roughly 1.6 million inhabitants. Unlike Benasal and Almazora, in Valencia most individuals have Spanish as their mother tongue. As it is one of the most popular tourist destinations in Spain, a wide range of nationalities and languages can be found in the area.

That being said, the languages of this study are not limited to the national and regional languages, but other foreign languages are also considered. Thus, the languages included in this study are Valencian - a dialectal variety of Catalan — as a minority language, Spanish as the official language of the state, English as the language of international communication, and other languages.

The objective of this study is twofold. On the one hand, the linguistic landscape of rural and urban settings is examined to determine the number of languages displayed as well as how the power and status of minority, national, and international languages are portrayed in these urban and rural settings. On the other hand, the study of these linguistic landscapes is aimed at examining how the coexistence of several languages may have an influence on language use.

The current paper departs from the following hypotheses:

(a) The linguistic landscape of Benasal portrays the preference of the Valencian language in monolingual and bilingual signs set up by local and regional authorities. The opposite occurs in the private sector, where Spanish is the language of communication.

(b) The linguistic landscape of Almazora is more likely to have bilingual and multilingual patterns in official and nonofficial signs, where Valencian is the dominant language. As to bottom-up signs, bilingual or multilingual instances are not likely to be identified given that Spanish is the preferred language.

(c) The linguistic landscape of Valencia is likely to have Spanish as the dominant language in monolingual, bilingual, and multilingual signs issued by official institutions. Similarly, most bilingual and monolingual signs are in Spanish, followed by English due to its prestige as an international language. On the contrary, Valencian-only signs may not appear on private enterprises.

The relevance of this research has to do with the implementation of language policies in urban and rural settings. The findings indicate that citizens' and tourists' origins may not only differ, but they also shape official and nonofficial language policies.

\section{Method}

\subsection{Materials}

As for the method, a corpus was developed for this study. The linguistic landscape of three municipalities was examined to address existing issues in urban and rural areas related to language contact, language dominance, and the distribution of official and foreign languages on private and public signs. To achieve this goal, a total of 185 pictures was collected. Some bottom-up signs were analysed as a combination of monolingual, bilingual, and multilingual signs since they belonged to the same business. 


\subsection{Procedure}

A coding scheme (based on Shohamy et al. 2010) was developed for this study. The variables included to codify the different pictures have to do with the number of languages, language and power relations, and the public or private origin of the signs.

Drawing on Ben-Rafael et al. (2006) classification the data were categorised in top-down and bottom-up signs (see Table 1). Top-down signs are official signs regulated by public institutions, whether national, regional, or local. These items were sub-classified as religious, educational, cultural, medical, or governmental. On the contrary, bottom-up signs are issued by private institutions; professionals can choose their brand language. The sub-categories analysed in the bottom-up signs were shops, bars, restaurants and cafés, academies, and billboards.

Table 1. Coding scheme.

\begin{tabular}{|c|c|c|}
\hline Category & Type of Item & Language \\
\hline \multirow{4}{*}{ Top-down } & Religious: churches, chapels & \multirow{4}{*}{ Monolingual, bilingual and multilingual } \\
\hline & Cultural: tourist and historical areas & \\
\hline & Medical: outpatient clinic & \\
\hline & Governmental: street names, traffic signs, schools & \\
\hline \multirow{4}{*}{ Bottom-up } & Shops: food, clothing & \multirow{4}{*}{ Monolingual bilingual and multilingual } \\
\hline & Bars, restaurants, and cafés & \\
\hline & Academies & \\
\hline & Billboards & \\
\hline
\end{tabular}

\section{Results}

The results of the study concerning the languages displayed on signs, language dominance, and language contact are now considered.

\subsection{Linguistic Repertoire}

\subsubsection{Top-Down Signs}

Concerning Benasal, nearly 72\% of top-down signs are monolingual, either in Valencian or in Spanish. They are unequally spread over the village. As can be observed in cultural and religious buildings, the frequency of Valencian (44\%) in monolingual signs is higher than that of Spanish $(28 \%)$ (Figure 1).

\section{Benasal: Top-down signs}

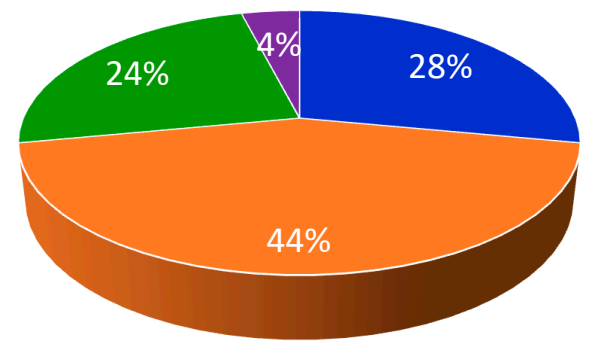

- Spanish - Valencian - Spanish-Valencian - English

Figure 1. Benasal: Top-down signs. 
Clear examples in Valencian include religious and historical buildings such as chapels (e.g., Capella de la Puríssima) and castles (e.g., Castell de la Mola 'Mola's castle'), respectively (Figures 2 and 3). On the contrary, monolingual signs in Spanish involve its well-known spa (Figure 4) and other historical signs (Figure 5). In some cases, tourists and locals are provided with a detailed explanation of the sites.

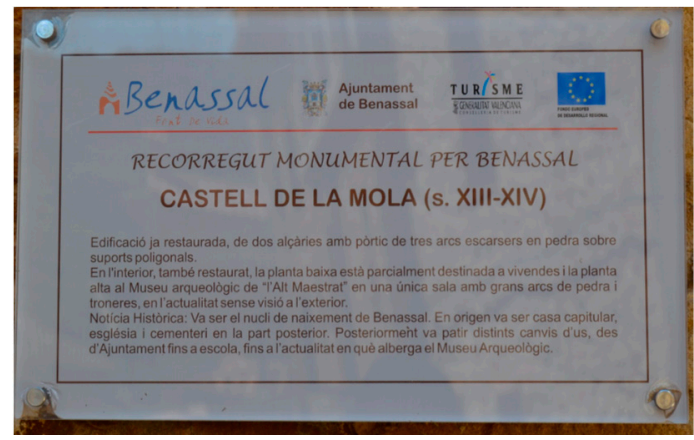

Figure 2. Benasal: Valencian-only sign on a castle.

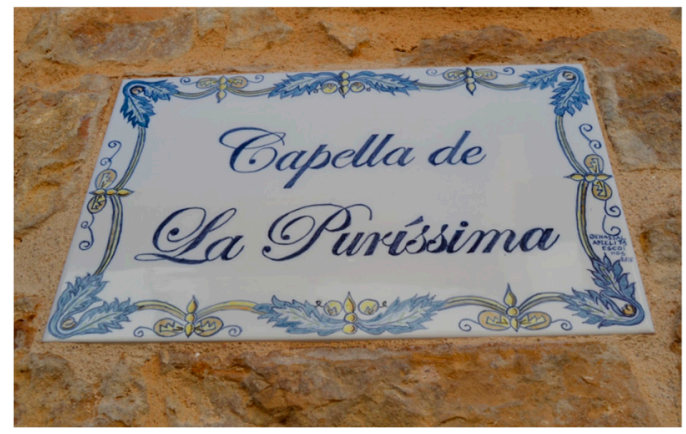

Figure 3. Benasal: Valencian-only sign on a chapel.

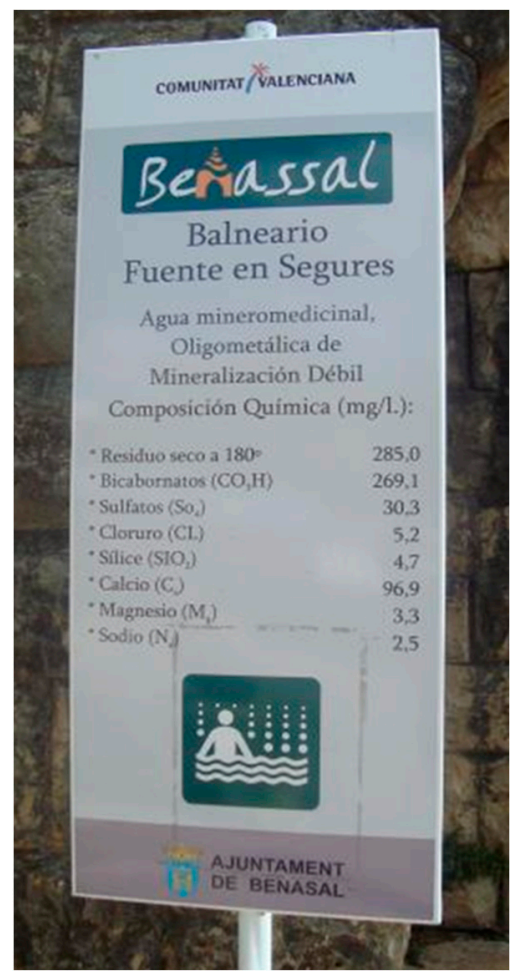

Figure 4. Benasal: Spanish-only sign on a spa. 


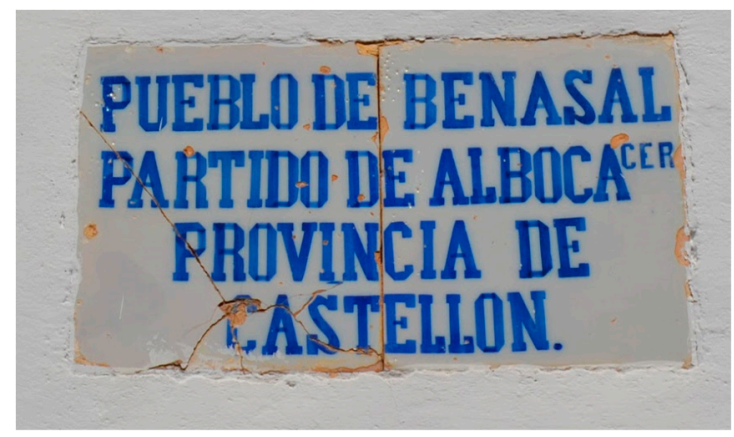

Figure 5. Benasal: Spanish-only historical sign.

The different linguistic policies that have been implemented since the 20th century have had an impact on the linguistic landscape of Benasal. When it comes to governmental signs, monolingual and bilingual street names were identified (Figures 6-8).

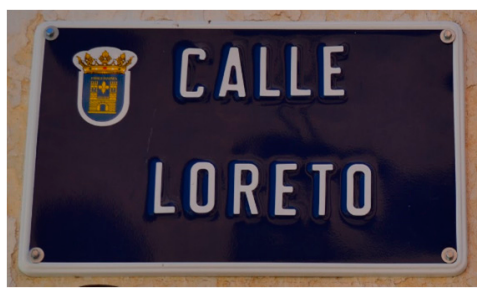

Figure 6. Benasal: Spanish-only street name.

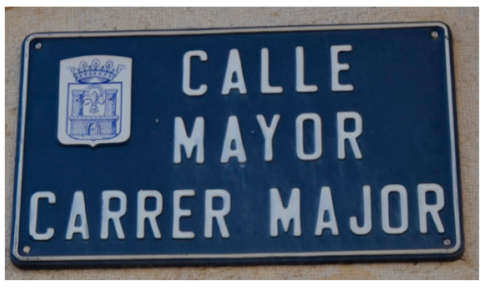

Figure 7. Benasal: Bilingual street name.

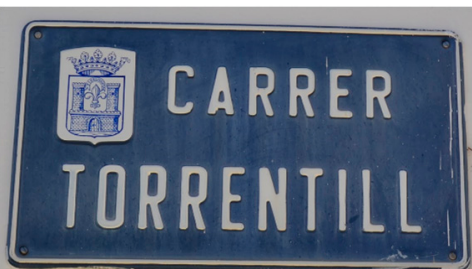

Figure 8. Benasal: Valencian-only street name.

As can be seen above, the number of languages in bilingual signs (24\%) is limited to Spanish and Valencian. Thus, the dominant language may vary depending on the time these governmental signs were issued. Evidence can be found in street names, plastic recycling containers (Figure 9), as well as in the Spanish postal service sign (i.e., Correos 'post office service') (Figure 10). 


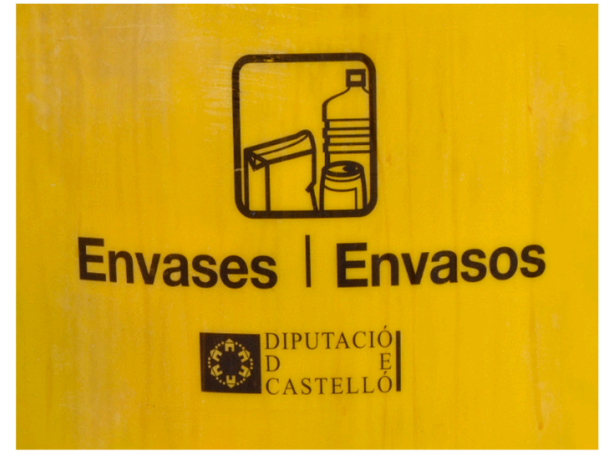

Figure 9. Benasal: Bilingual sign on a plastic recycling container.

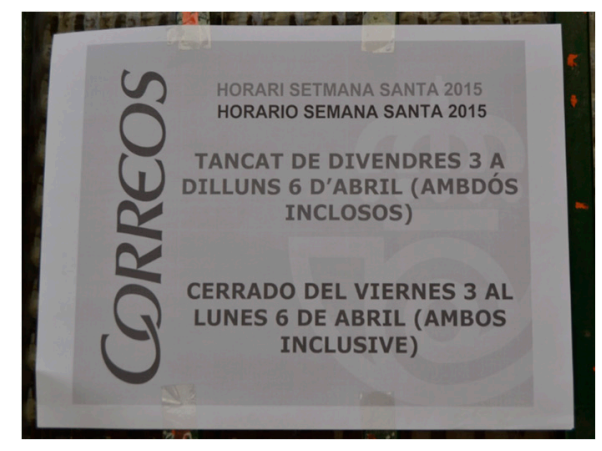

Figure 10. Benasal: Bilingual sign on a post office document.

For most of the 20th century, the first linguistic policies promoted the use of Spanish (Figure 2). Towards the end of the 20th century the regional government regulated the languages included in bilingual signs. Figure 3 shows the power of Spanish over Valencian as it is the first language appearing on the top of the sign, whereas the opposite occurs in Figures 5 and 6 . These latter seem to be more recent signs, as Valencian is the first language used in an attempt to preserve the village's local identity. At the beginning of the 21st century, there was a trend to foster the use of Valencian as the main language within that linguistic community. Despite this heterogeneous use of languages, it can be inferred that comprehension is not hindered.

Multilingual signs containing Spanish, Valencian, and English could not be found. So far, the English language is used once, as can be seen in the Tourist Info sign below (Figure 11). The main reasons for this have to do with a generational gap and tourists' origins. The proportion of elderly living in this village who did not have the opportunity to learn a foreign language is higher than the proportion of young people. In addition, tourism is primarily national and regional.

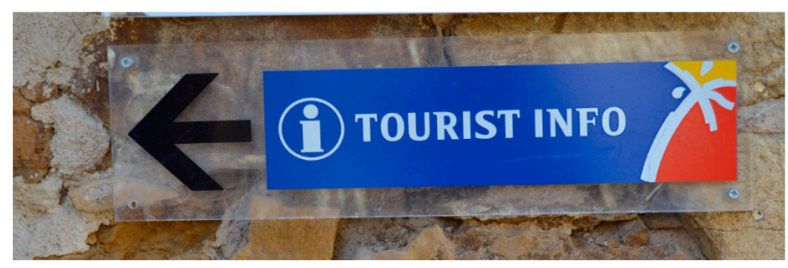

Figure 11. Benasal: English-only sign.

Focusing on Almazora, the vast majority of top-down signs are monolingual (92\%) (Figure 12). Cultural, medical, and governmental monolingual signs show the overwhelming use of the Valencian language in this town (67\%). Public spaces including the central market, a local infant school, a hermitage path, and a museum, among others, are all signed in Valencian. 


\section{Almazora: Top-down signs}

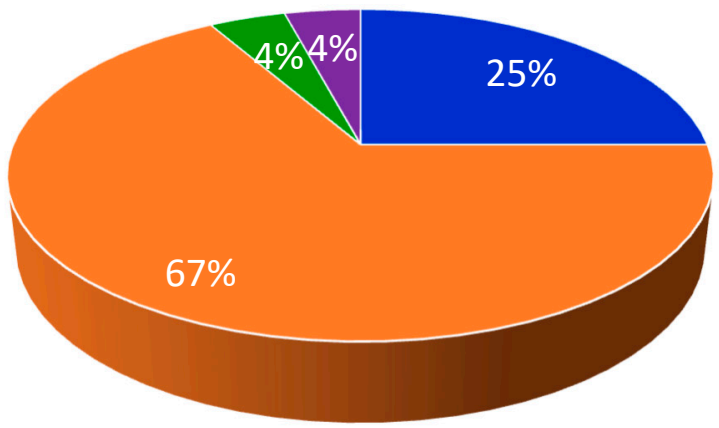

- Spanish Valencian - Spanish-Valencian English

Figure 12. Almazora: Top-down signs.

The regional legislation of the Valencian Community states that Valencian-speaking areas should implement linguistic policies that boost exposure to the minority language. This initiative is key to making Valencian (67\%) more visible than Spanish (25\%). Such monolingual signs include traffic and medical signs that can be observed as a combination of signs. Clear examples involve an outpatient clinic where monolingual signs in Spanish and Valencian can be observed. More specifically, the language employed in the official name of this medical building is Valencian (Figure 13) rather than Spanish. However, Spanish is used to provide patients with general information of the healthcare fields offered in this area (Figure 14). In this sense, similar signs that aim at generating bilingual experiences are spread throughout the town.

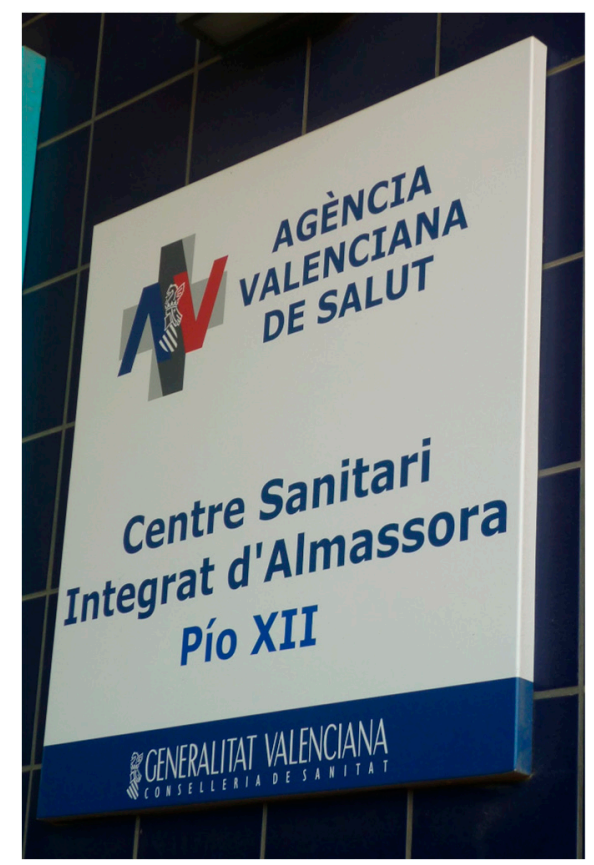

Figure 13. Almazora: Valencian-only sign on an outpatient clinic. 


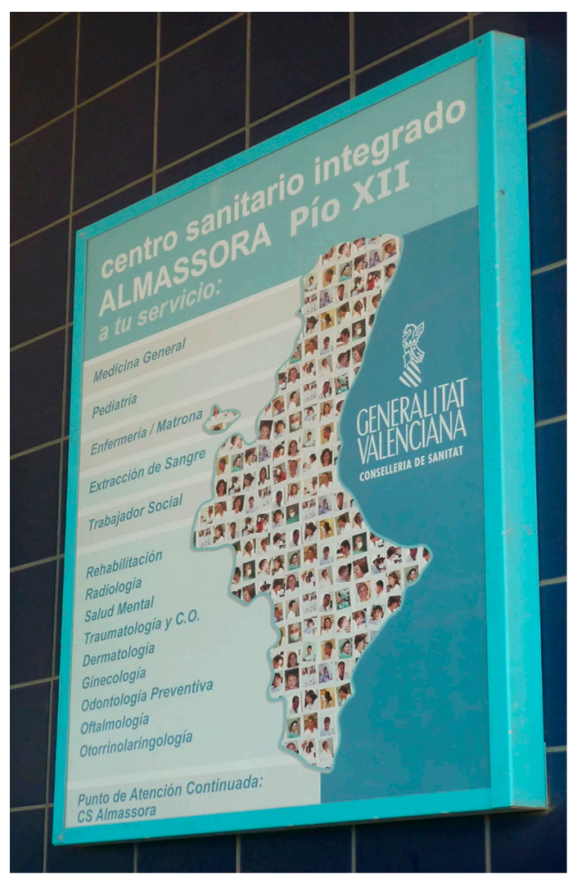

Figure 14. Almazora: Spanish-only sign on an outpatient clinic.

Contrary to all expectations, the distribution of bilingual and multilingual signs is barely noticeable. As in Benasal, bilingual signs (4\%) correspond to street names regulated by the town council, where Valencian is the dominant language (Figures 15 and 16). Even though there are no official signs where Spanish or Valencian are combined with other foreign languages, English is displayed in the monolingual Tourist Info sign.

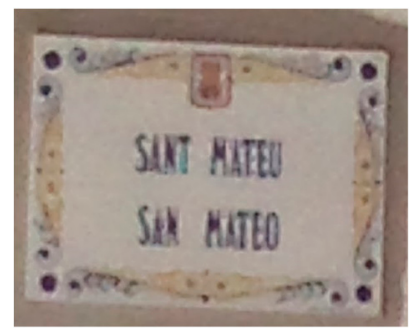

Figure 15. Almazora: Bilingual street name.

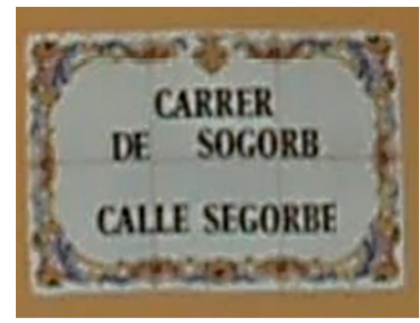

Figure 16. Almazora: Bilingual street name.

Even though the population of the city by and large has Spanish as its mother tongue, policies have been developed to include the minority language. In the centre of Valencia, approximately $55 \%$ of the signs are monolingual (Figure 17). There seems to be a balance in the use of Spanish-only (22\%) and Valencian-only (33\%) items. Although both languages are co-official, Valencian is still the preferred language to preserve the identity of the city. 


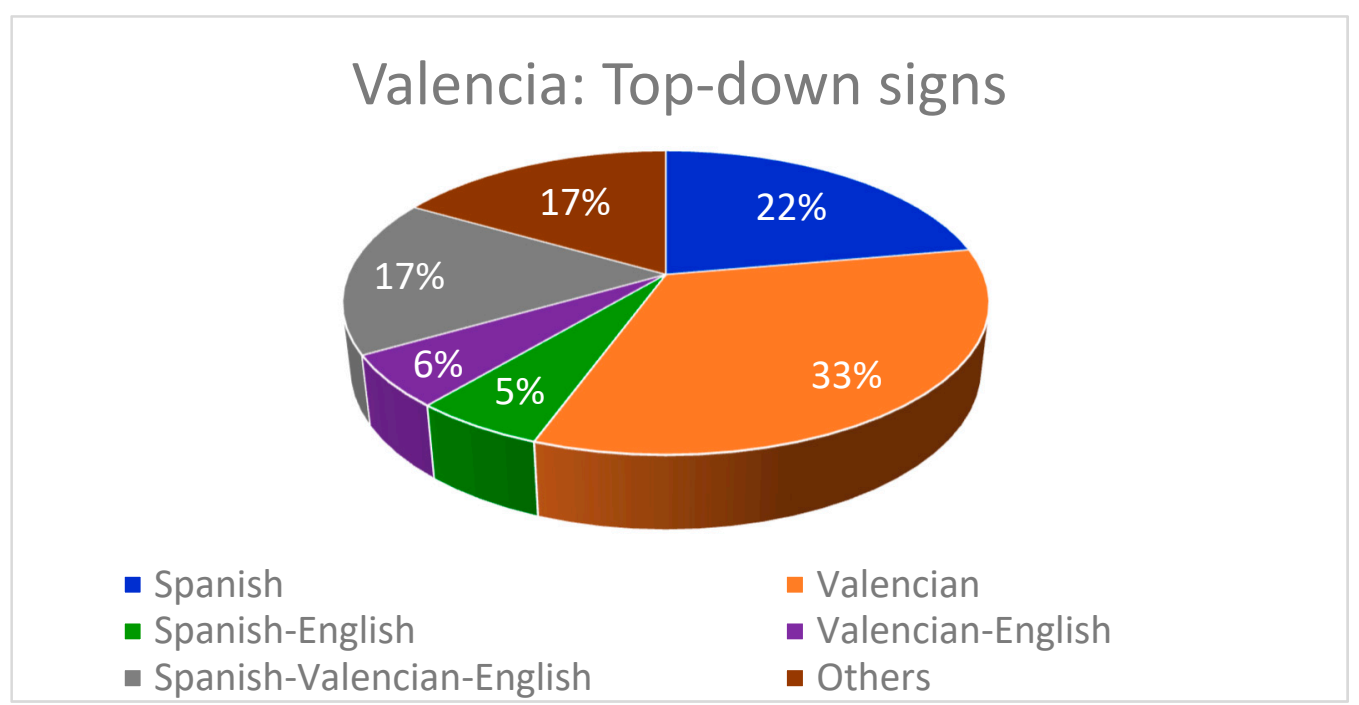

Figure 17. Valencia: Top-down signs.

Both languages can be found in historical, religious, and governmental signs. For instance, Valencian is the language displayed in the archaeological centre (Figure 18). By contrast, Spanish can be seen in the traders' market, which was declared a UNESCO World Heritage Site (Figure 19).

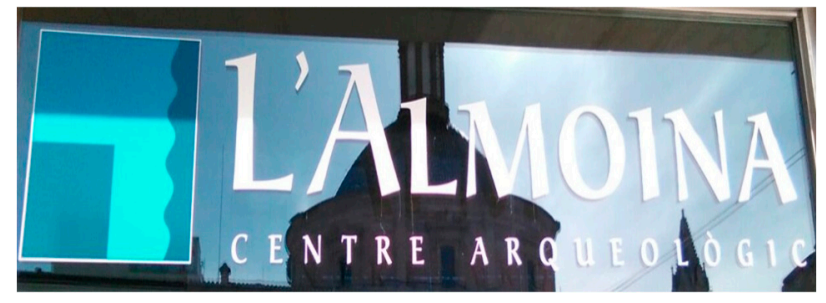

Figure 18. Valencia: Valencian-only sign on an archeological centre.

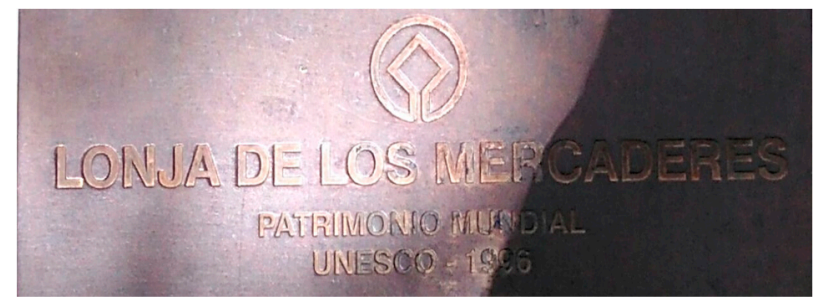

Figure 19. Valencia: Spanish-only sign on a traders' market.

The distribution of bilingual signs in Valencia (11\%) is higher than in Almazora. As the centre of Valencia is an eminent tourist area, languages other than Spanish and Valencian are used, particularly English. Hence, it is possible to find bilingual signs combining Spanish and English, and Valencian and English. The sign in Figure 20 is predominantly for national and international tourists. The font size and colour are the same for both languages; however, Spanish seems to be the more powerful language as it is on the top. 


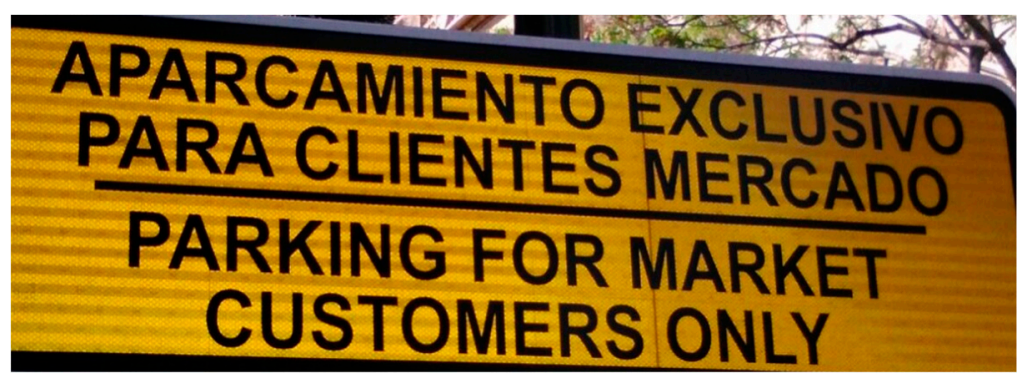

Figure 20. Valencia: Spanish-English sign on a car park.

Figure 21 shows a governmental sign in Valencian and English. As can be observed, this is a combination of two signs. The sign on the top has to do with the name of the organisation, but the focus of this picture is on the sign below, where English is the first language appearing. It seems to be addressed to locals and international individuals who work with these languages on a regular basis, especially because it is a regional institution.

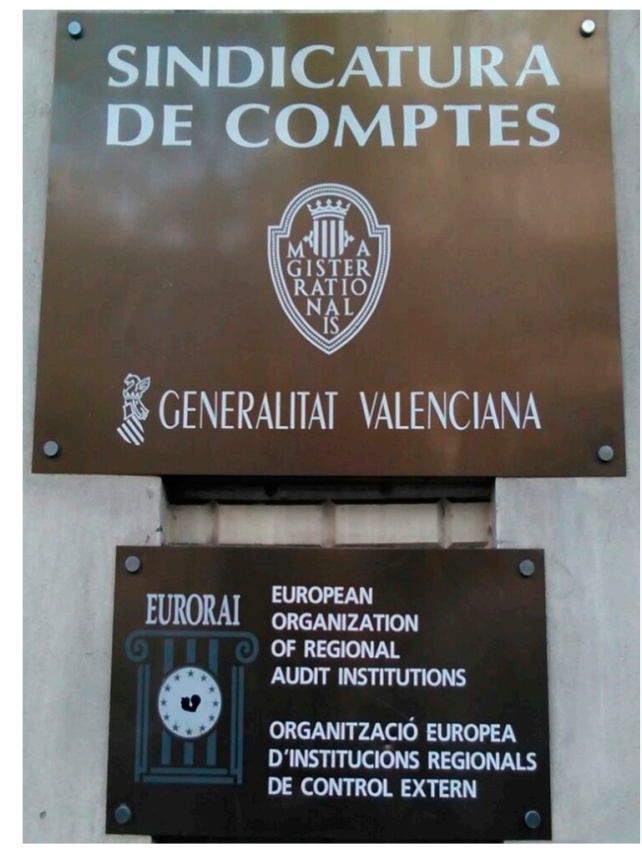

Figure 21. Valencia: Bilingual sign on an official institution.

Multilingualism (30\%) in Valencia involves the use of Spanish, Valencian, and English (24\%). The power relations established suggest that Spanish is the dominant language as it is the first language employed to address locals and tourists (Figure 22). The inclusion of the minority language involves the use of italics and a light colour, which makes it difficult to read. However, even though English is the third language, it can be read without difficulty. 


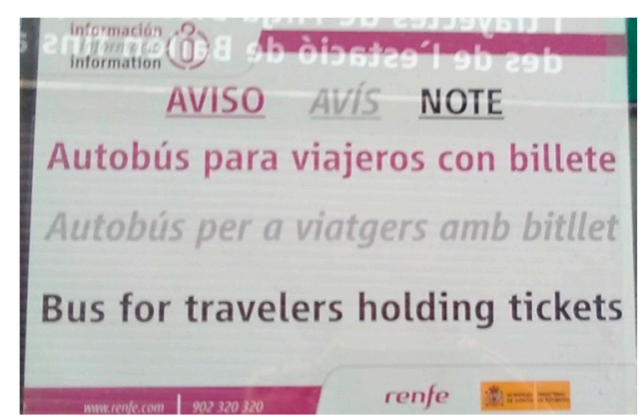

Figure 22. Valencia: Trilingual sign on a bus station.

Linguistic diversity is also determined by the presence of other international languages in multilingual signs (6\%). Figure 23 below shows a wide range of languages including Spanish, Valencian, English, French, Italian, and German. The inclusion of these languages may be related to the main nationalities of the tourists who visit Valencia. The first three languages have the same font size, whereas the font size of the rest of the languages seems to be smaller.

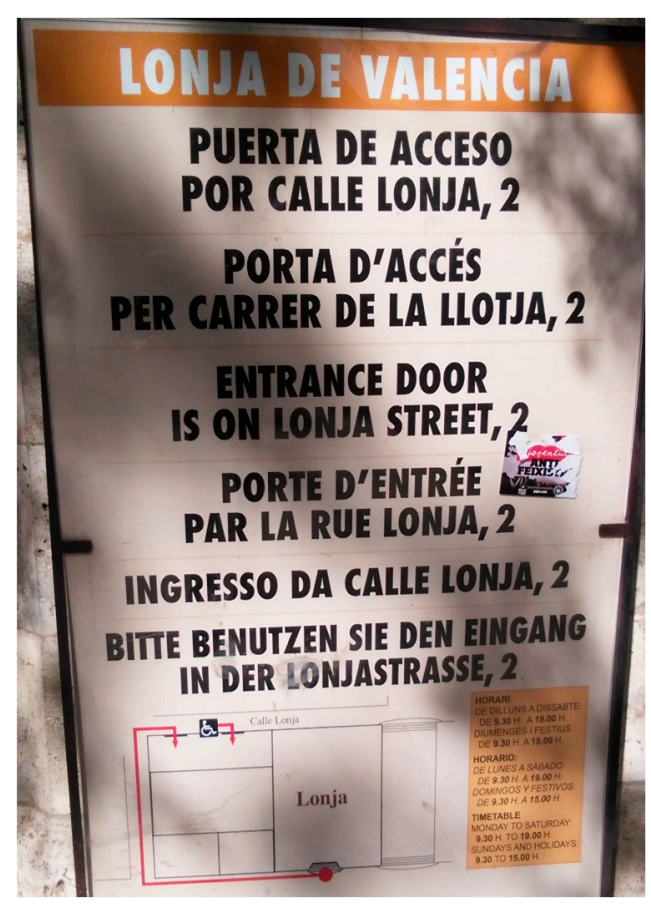

Figure 23. Valencia: Multilingual sign on a traders' market.

\subsubsection{Bottom-Up}

Regarding bottom-up signs, clear differences can be found in terms of bilingual and multilingual patterns. In Benasal, a total of $67 \%$ of bottom-up signs are monolingual whilst the remaining $33 \%$ are bilingual signs (Figure 24). 


\section{Benasal: Bottom-up signs}

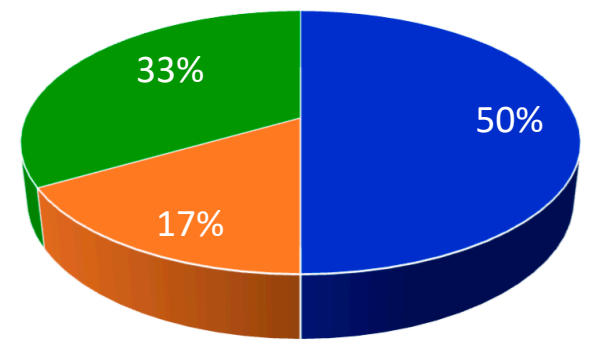

- Spanish - Valencian - Spanish-Valencian

Figure 24. Benasal: Bottom-up signs.

Nonofficial signs in Benasal are characterised by the predominance of Spanish-only items (50\%). The presence of Spanish in the private sector does not only have to do with the establishment of international companies but also with the opening of businesses that took place during the second half of the 20th century. This is the case of bakeries and bank offices whose brand name is in Spanish (Figures 25 and 26). Interestingly, the role of the Valencian language in the private sector is not as frequent as expected $(17 \%)$.

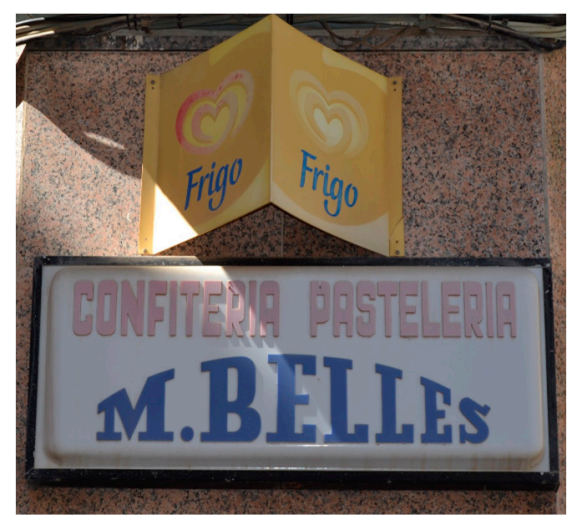

Figure 25. Benasal: Spanish-only sign on a confectionery and candy store.

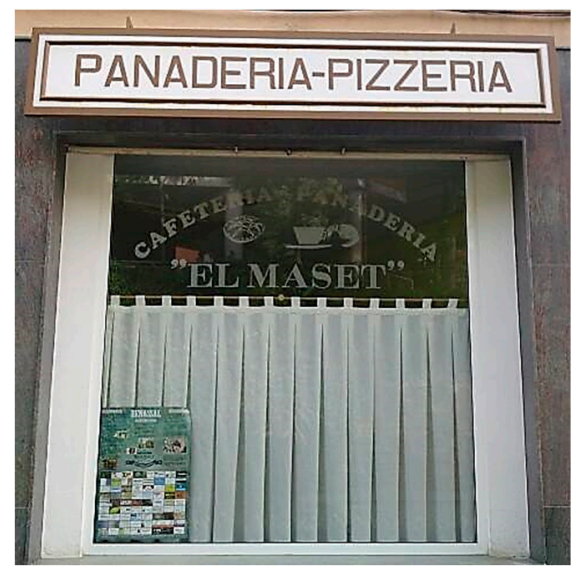

Figure 26. Benasal: Valencian-only sign on a bakery. 
Bilingual signs are addressed to potential customers. Hence, local businesses try to develop appropriate communication strategies by addressing individuals in Spanish and Valencian. In Figures 27 and 28 there is no doubt that Valencian is the most relevant language, as it highlighted in bold, whereas its translation in Spanish may appear in italics and different colours.

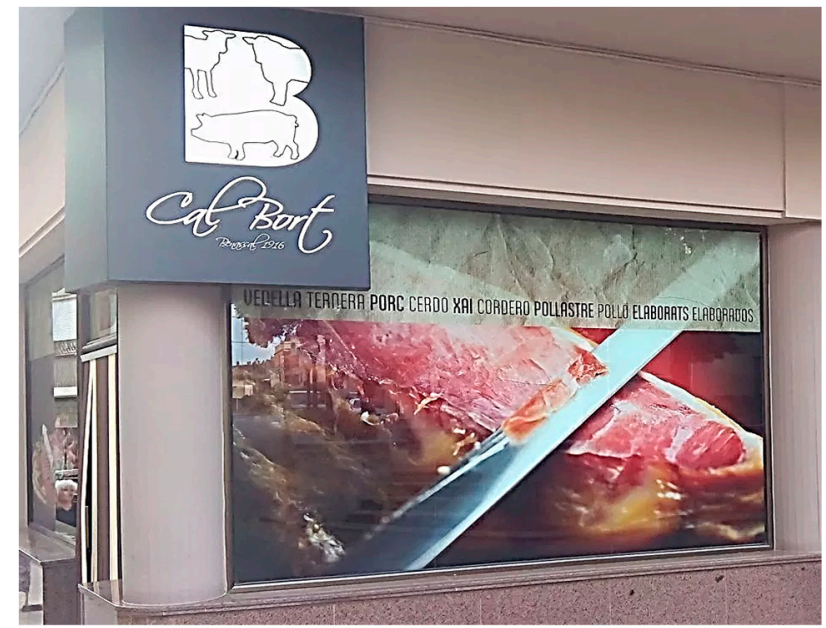

Figure 27. Benasal: Bilingual sign on a butchery.

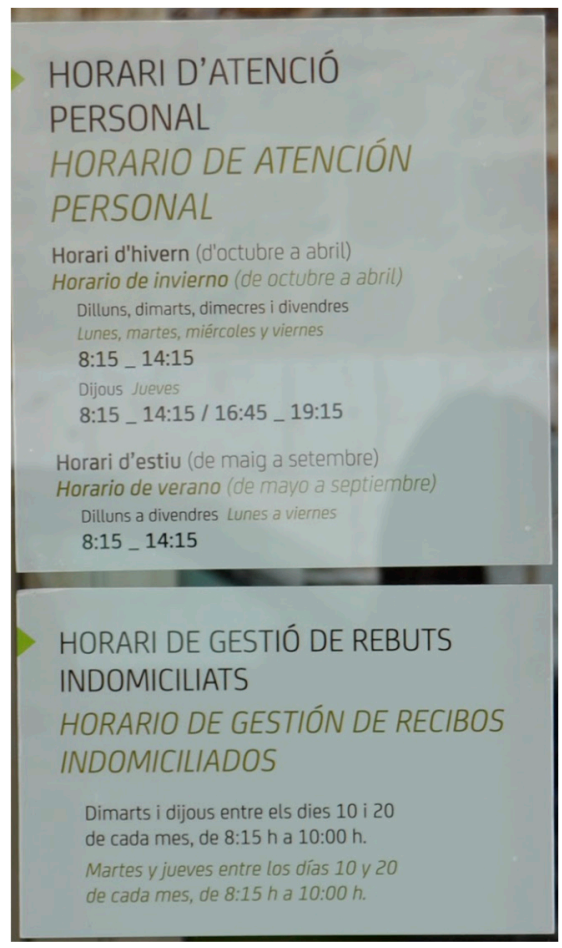

Figure 28. Benasal: Bilingual sign on a bank office.

Unlike in Benasal, there is no considerable differences in the use of Valencian-only (27\%) and Spanish-only (23\%) signs in Almazora (Figure 29). Valencian patterns are found in a variety of areas, such as architecture, podiatry, butchery, haberdashery, bakeries, and language academies, among others. Similarly, Spanish items can be identified in dentists, cafés, hairdressers, and butcheries. 


\section{Almazora: Bottom-up signs}

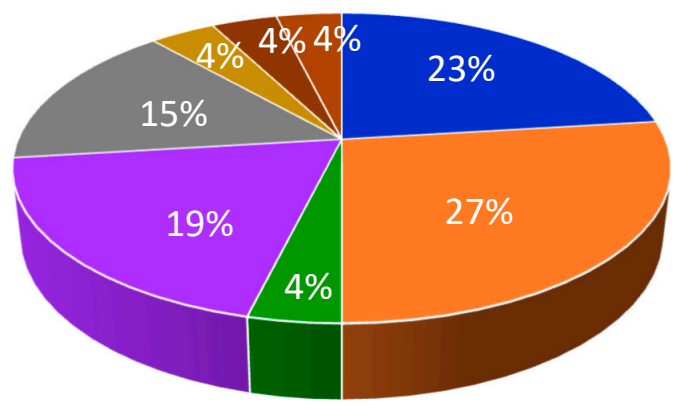
- Spanish
- Valencian
- English
- Spanish-Valencian
- English-Spanish
- English-Valencian
- Romanian-Spanish
- Others

Figure 29. Almazora: Bottom-up signs.

The recurrent pattern in bilingual signs (42\%) has to do with the two co-official languages of the region. Some shop names are in Valencian, but Spanish is the selected language to communicate additional information. Evidence can be found in health food (Figure 30) and stationery shops (Figure 31).

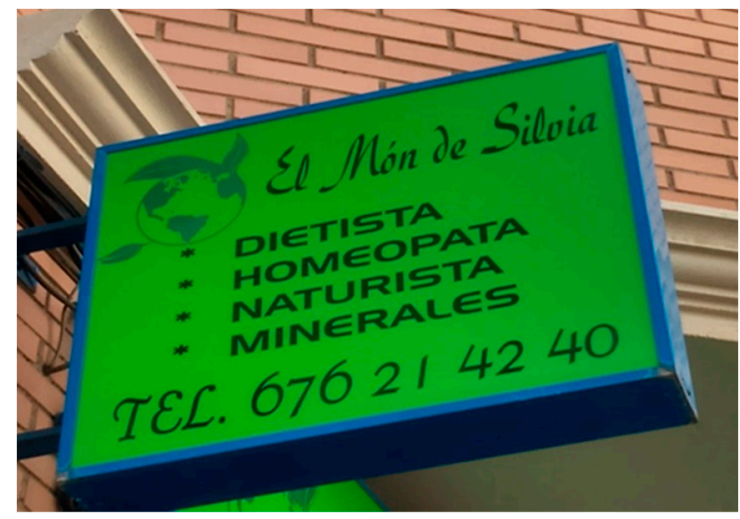

Figure 30. Almazora: Bilingual sign on a health food shop.

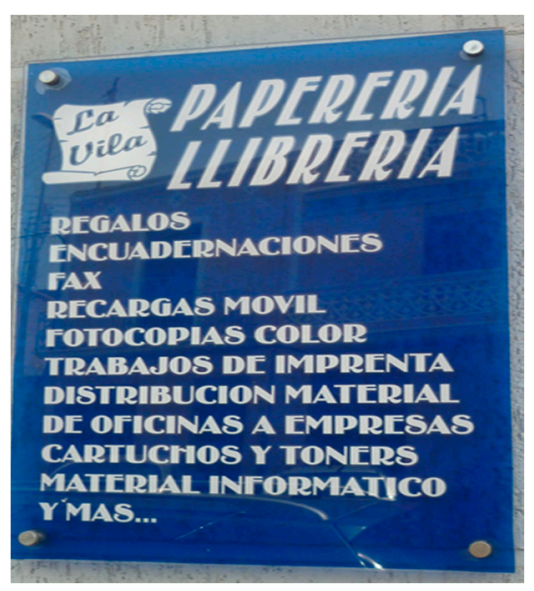

Figure 31. Almazora: Bilingual sign on a stationery shop. 
Notwithstanding, bilingual signs in English-Valencian (4\%), English-Spanish (15\%), and Romanian-Spanish (4\%) can be observed. English is the dominant language in the items below as English is the language of instruction in these language academies. In Figure 32, Valencian patterns seem to be smaller, whereas in Figure 33 Spanish is highlighted with a different colour and font size.

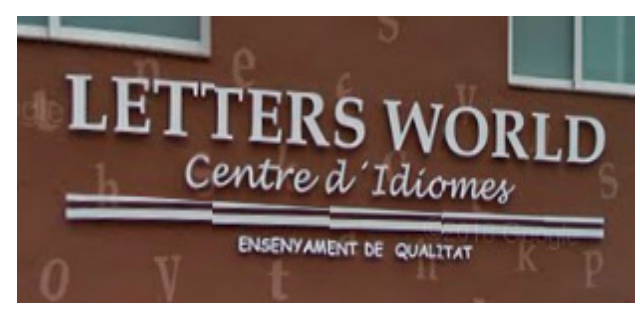

Figure 32. Almazora: English-Valencian sign on a language academy.

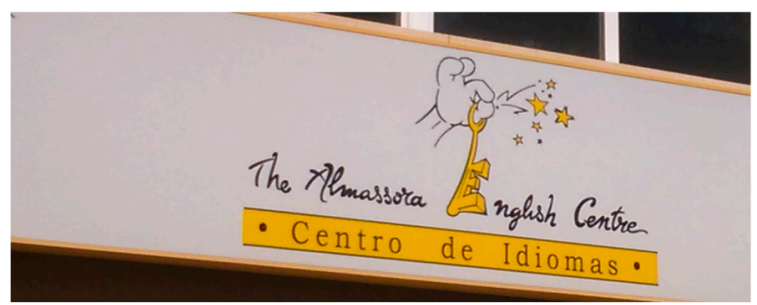

Figure 33. Almazora: English-Spanish sign on a language academy.

Figure 34 is a Romanian-Spanish sign. The flag and the shop name are Romanian rather than Spanish, which is used to attract the Romanian community living in Almazora as well as local customers. Other international languages such as Italian appear as the only language on certain signs (Figure 35).

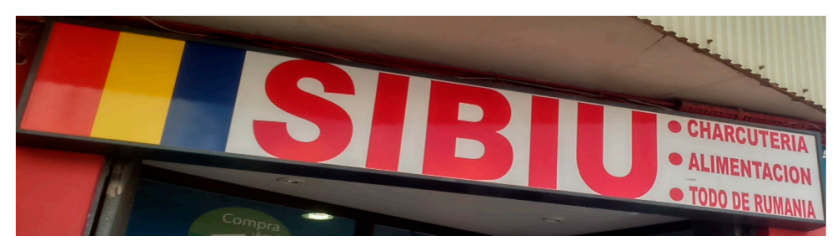

Figure 34. Almazora: Romanian-Spanish sign on a butchery.

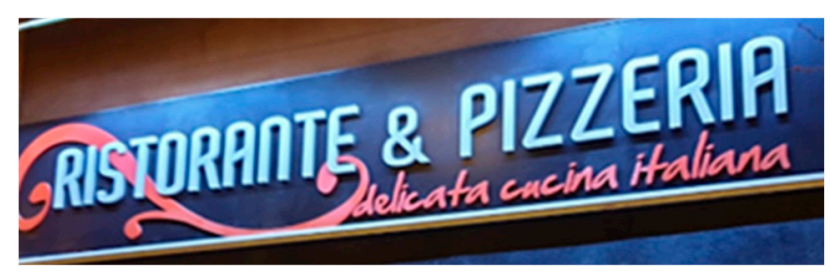

Figure 35. Almazora: Italian sign on a restaurant.

When it comes to Valencia, $65 \%$ of nonofficial signs are monolingual. The linguistic landscape of the city seems to be dominated by Spanish (26\%), closely followed by Valencian (23\%) and English (16\%) (Figure 36). 


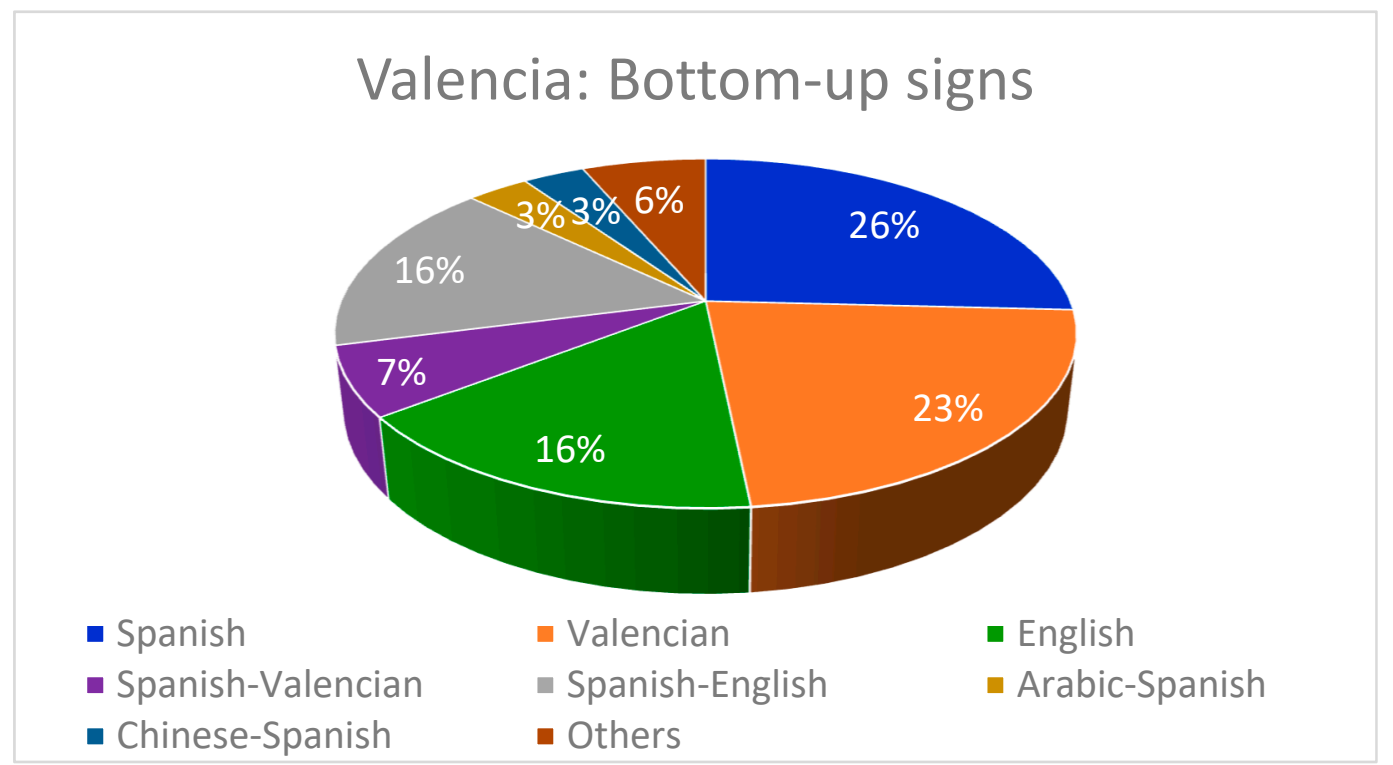

Figure 36. Valencia: Bottom-up signs.

The bilingual landscape $(29 \%)$ in Valencia is determined by private initiatives, since they are concerned with strategic marketing decisions dealing with companies' international orientation. Taking this into account, the most predominant languages in bottom-up signs include Spanish, Valencian, and English. Figure 37 is a Spanish-English sign. As can be observed, the properties of the font-size employed in this bilingual item reveal that Spanish is the dominant language. Actually, the name of the bookshop, which is in English, is smaller.
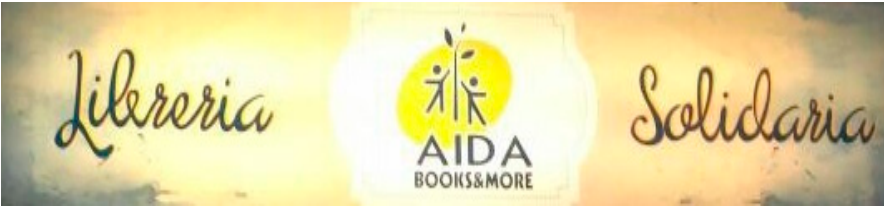

Figure 37. Valencia: Spanish-English sign on a bookshop.

Efforts to promote the minority language have also been made by regional supermarkets, where products are signed in both co-official languages. No differences in terms of font properties are recognised, so it can be stated that Spanish and Valencian have the same status (Figure 38).

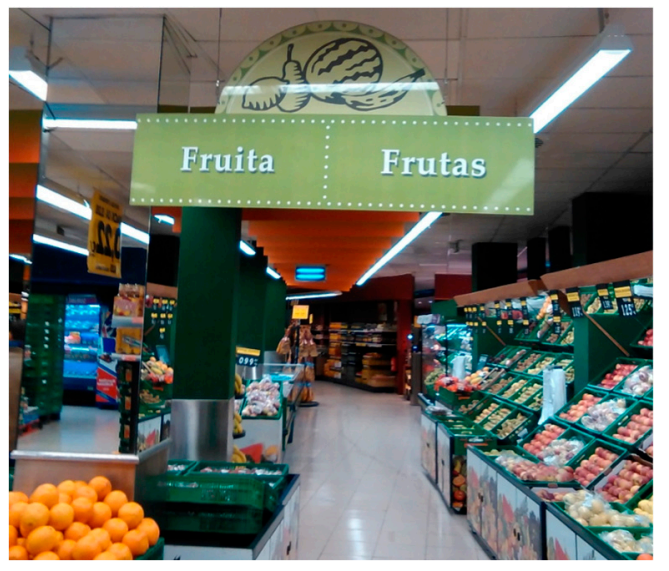

Figure 38. Valencia: Bilingual sign in a supermarket. 
Other languages used in nonofficial signs are Arabic, Italian, and Chinese. A clear example is that of the Arabic butchery (Figure 39). The presence of both Arabic and Spanish indicates that the patrons of this business are local and Arabic communities. Nonetheless, the use of Arabic is limited to translate the Spanish name, with the latter also being used to describe the kind of products they offer.

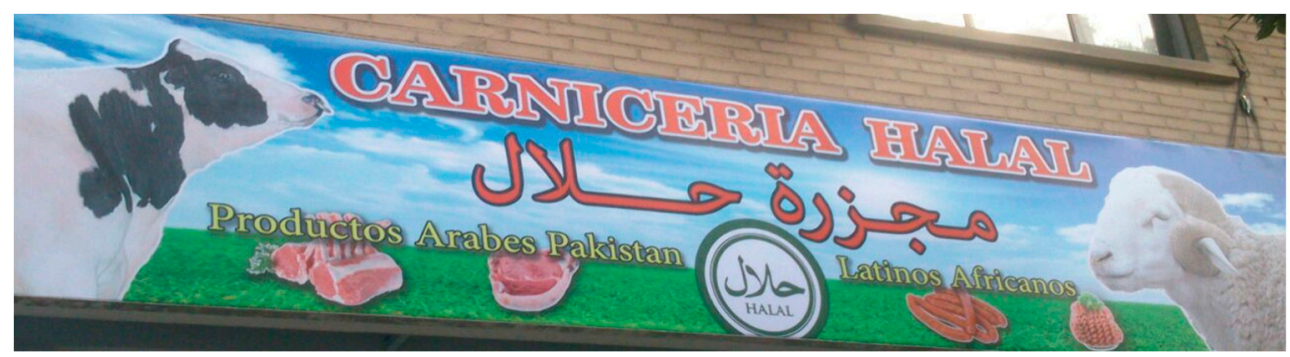

Figure 39. Valencia: Arabic-Spanish sign on a butchery.

\subsection{Language Contact}

The co-existence of a number of languages in the same area may lead to language contact or mixing in terms of syntax and lexicon. This process can be observed in the three municipalities under study.

In Benasal, language contact occurs between Spanish and Valencian. Surprisingly, this phenomenon is observed in top-down signs, which are expected to be precise within the rules of the languages used. Thus, even though there exist signs that appear to be completely written in Spanish, some lexical items are introduced in Valencian. Despite having a Spanish version, the Valencian name is used in Figure 40. Another example is found in the laundry sign, where the century is described in the minority language (Figure 41).

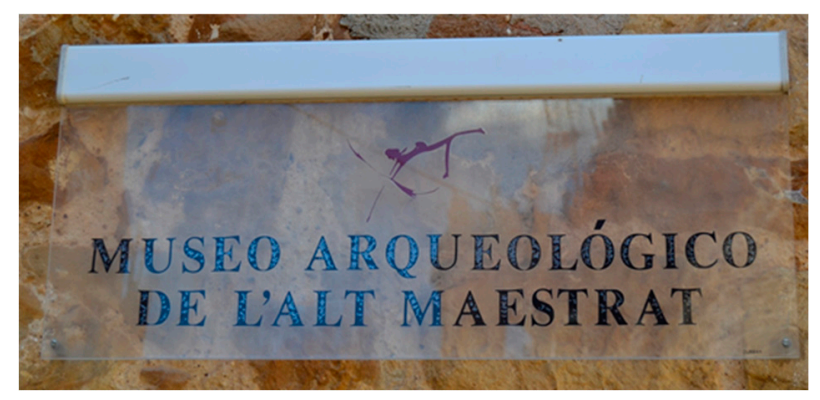

Figure 40. Benasal: Language contact on a museum sign.

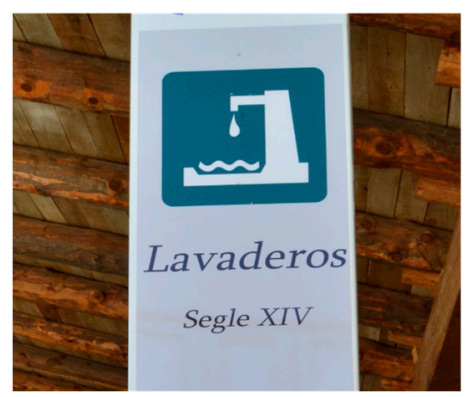

Figure 41. Benasal: Language contact on a laundry sign.

In Almazora, a different combination of languages can be recognised in bottom-up signs. For instance, the lexical borrowing 'stop' used in a driving school sign has been adapted to Spanish spelling (Figure 42). This is a strategy to catch potential users who would not pronounce the starting liquid " $\mathrm{s}$ ", but would change the phonology of the term by adding an " $\mathrm{e}$ " sound. 


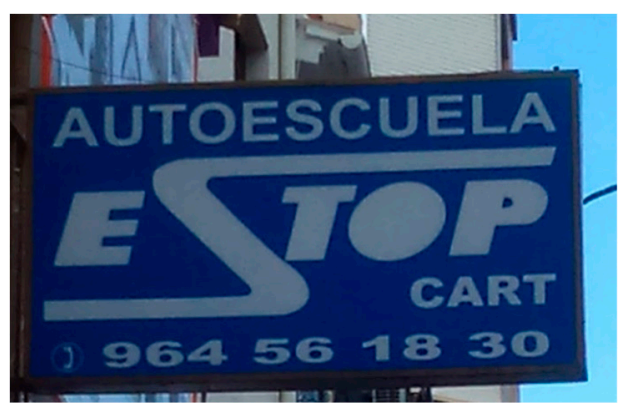

Figure 42. Almazora: Language contact on a driving school sign.

The impact of bilingualism in the linguistic landscape can also be seen in Valencia. At a syntactic level, it can be seen how English rules are followed given that the Spanish adjective is placed before the noun (Figure 43).

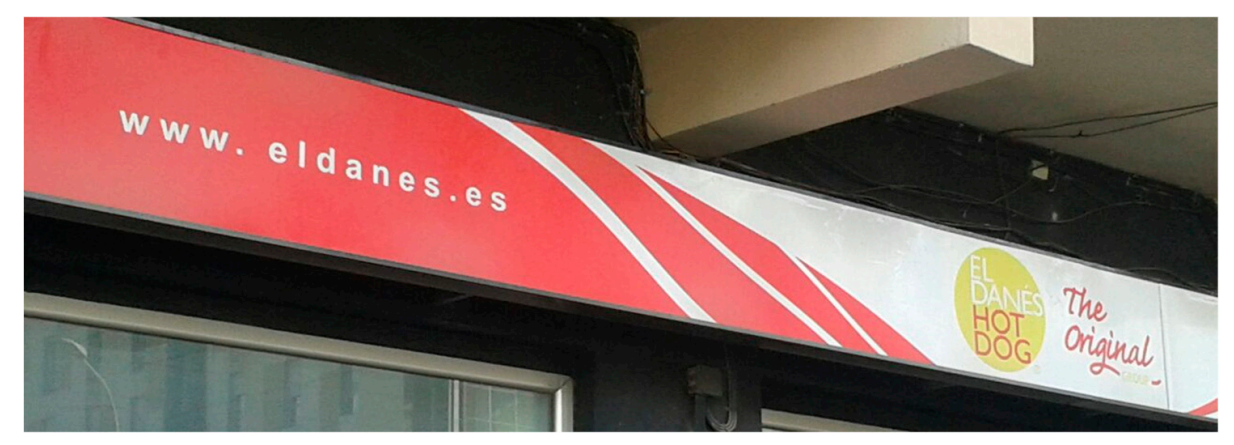

Figure 43. Valencia: Language contact on a food shop sign.

\section{Discussion and Conclusions}

Focusing on the number of languages displayed on signs, several languages can be identified: Valencian as the minority language, Spanish as the national language, and other foreign languages. English is the most prestigious international language in Almazora and Valencia, which tends to appear alongside Spanish. In this sense, the use of English in top-down signs may have a communicative function with tourists, while its use in commercial signs evidences their international orientation, success, or sophistication (Piller 2003). Languages other than English, such as Arabic, Romanian, or Italian, which are only placed by private initiative, are less frequent and are limited to urban contexts. Thus, it can be inferred that if Arabic is used, it is likely to be a bottom-up sign set in areas where those linguistic communities live.

As to power and language relations, the findings show that the power of the two co-official languages is reinforced by public signs, whereas rich linguistic diversity is shown in private signs. All municipalities have Valencian as the most prominent language in top-down signs, followed by Spanish as the second language. In third place, the presence of English is barely noticeable in Benasal and Almazora in contrast to Valencia, where it plays a significant role in tourism. The order of languages differs when it comes to bottom-up signs. Spanish is strongly present in Benasal and Valencia as the first language, followed by Valencian and English, whereas Valencian is much more salient in Almazora, followed by Spanish and English. The prevailing pattern in Benasal and Almazora concerning bilingual items is Valencian-Spanish. Valencian is thus the dominant language in these small urban and rural settings. Unlike Benasal and Almazora, bilingual patterns show that Spanish is the recurrent language in both official and nonofficial signs.

Language mixing occurs in areas where multiple languages coexist. Borrowing and adaptation from one language to another are found at lexical and syntactical levels. The fact that such a phenomenon is observed in official signs may reflect the need for local authorities to preserve their 
identity. In bottom-up signs, the incorporation of these traits is designed to attract potential clients by stressing their international and sophisticated status (Piller 2003).

All things considered, even though the weaker or stronger presence of Valencian in private and public institutions depends on whether Spanish or Valencian is the most predominant language in a certain area (Statute of Autonomy of the Region of Valencia), it seems that the linguistic policy is not implemented homogeneously. The languages displayed on signs have an impact on society's perception and attitudes towards them. Further research on the linguistic landscape of the Valencian Community is needed to determine the efficiency of its regional language policy.

Funding: This research received no external funding.

Conflicts of Interest: The author declares no conflict of interest.

\section{References}

Ben-Rafael, Eliezer, Elana Shohamy, Muhammad Hasan Amara, and Nira Trumper-Hecht. 2006. Linguistic landscape as symbolic construction of the public space: The case of Israel. International Journal of Multilingualism 3: 7-30. [CrossRef]

Cenoz, Jasone, and Durk Gorter. 2006. Linguistic landscape and minority languages. International Journal of Multilingualism 3: 67-80. [CrossRef]

European Commission. 2015. Language Teaching and Learning in Multilingual Classrooms. Education and Training. Available online: http://ec.europa.eu/dgs/education_culture/repository/languages/library/studies/ multilingual-classroom_en.pdf (accessed on 6 May 2019).

European Parliament. 2017. Research for CULT Committee-Minority Languages and Education: Best Practices and Pitfalls. Available online: http://www.europarl.europa.eu/RegData/etudes/STUD/2017/585915/IPOL_ STU(2017)585915_EN.pdf (accessed on 6 May 2019).

Gorter, Durk, ed. 2006. Linguistic Landscape: A New Approach to Multilingualism. Bristol: Multilingual Matters.

Huebner, Thom. 2006. Bangkok's linguistic landscapes: Environmental print, codemixing and language change. International Journal of Multilingualism 3: 31-51. [CrossRef]

Landry, Rodrigue, and Richard Y. Bourhis. 1997. Linguistic landscape and ethnolinguistic vitality: An empirical study. Journal of Language and Social Psychology 16: 23-49. [CrossRef]

Piller, Ingrid. 2003. 10. Advertising as a site of language contact. Annual Review of Applied Linguistics 23: 170-83. [CrossRef]

Shohamy, Elana Goldberg, Eliezer Ben-Rafael, and Monica Barni, eds. 2010. Linguistic Landscape in the City. Bristol: Multilingual Matters.

(C) 2019 by the author. Licensee MDPI, Basel, Switzerland. This article is an open access article distributed under the terms and conditions of the Creative Commons Attribution (CC BY) license (http://creativecommons.org/licenses/by/4.0/). 